\title{
DESAFIOS ÉTICOS E METODOLÓGICOS EM PESQUISAS SOBRE LETRAMENTO DO PROFESSOR: PROVOCAÇÓES EM BUSCA DE NOVOS CAMINHOS
}

\author{
DESAFÍOS ÉTICOS Y METODOLÓGICOS EN INVESTIGACIONES SOBRE LITERACIDAD DE \\ DOCENTES: PROVOCACIONES EN BUSCA DE NUEVOS CAMINOS
}

ETHICAL AND METHODOLOGICAL CHALLENGES IN THE RESEARCH ON TEACHERS' LITERACY -Opening NEW PATHS

Paula Baracat De Grande
Graduada em Letras, mestre e
doutora em Linguística Aplicada,
Instituto de Estudos de Linguagem,
Universidade Estadual de Campinas
(IEL-UNICAMP).
Rua Doutor Elias Cesar 125, apto
1003, Caiçaras, Londrina-PR
E-mail: pauladegrande@gmail.com

Marília Curado Valsechi

Licenciada em Letras (Português/

Espanhol), Universidade Estadual

Paulista Júlio de Mesquita Filho.

Mestre e doutora em Linguística

Aplicada, Instituto de Estudos da Linguagem, Universidade Estadual de Campinas. Professora de Português e Espanhol do Instituto Federal do Paraná (IFPR).

Rua Benjamin Constant, 1717, Apto. 18, Centro, Londrina, PR marilia.valsechi@ifpr.edu.br https://orcid.

org/0000-0002-5254-2827

Carolina Assis Dias Vianna Graduada em Letras, mestre e doutora em Linguística Aplicada, Instituto de Estudos de Linguagem, Universidade Estadual de Campi-

\begin{abstract}
RESUMO
Nosso objetivo é realizar um ensaio para discutir sobre os desafios éticos e metodológicos em pesquisas realizadas na área dos Estudos de Letramento, no campo da Linguística Aplicada, com base no desenho de pesquisas realizadas no Grupo Letramento do Professor. Preocupado com a perspectiva ética no fazer investigativo, o campo dos Estudos de Letramento, em mais de duas décadas, tem se orientado a compreender e atuar em cenários nos quais a escrita (re) instaura tensões e conflitos que historicamente marginalizaram um grande contingente das populações latino-americanas. Na discussão dos aspectos éticos das pesquisas sobre letramento e formação do professor, destacamos a importância da visibilização das relações de poder em cenários desiguais de modo a contribuir para o fortalecimento de grupos sociais minoritarizados ou subalternizados, como professores em formação e, com isso, repensar o papel do pesquisador ao escolher investigar tais grupos.
\end{abstract}

Palavras-chaves: ética em pesquisa; metodologia; letramento; linguística aplicada.

\section{RESUMEN}

Nuestro objetivo es realizar un ensayo para discutir los desafíos éticos y metodológicos en trabajos de investigación en el área de los Estudios de Literacidad, en el campo de la Lingüística Aplicada, con base en el diseño de investigaciones realizadas en el grupo Letramento do Professor. Interesado en la perspectiva ética del quehacer investigativo, el campo de los Estudios de Literacidad se ha orientado, por más de dos décadas, a comprender y actuar en escenarios en los cuales la escritura (re)instaura tensiones y conflictos que marginaron a lo largo de la historia a un gran sector de las poblaciones latinoamericanas. En la discusión sobre los aspectos éticos de las investigaciones sobre literacidad y formación del profesor, destacamos la importancia de visibilizar las relaciones de poder en escenarios desiguales con el fin de contribuir al afianzamiento de grupos sociales 
nas (IEL-UNICAMP). Autora de livros didáticos de Língua Portuguesa para o ensino básico.

Rua Francisco Cruz, 448/91, Vila

Mariana, São Paulo, sP

carol_assis_dias@yahoo.com.br minoritarizados o subalternizados, como los docentes en formación y, con ello, repensar el rol del investigador al elegir investigar tales grupos.

Palabras claves: ética en la investigación; metodología; literacidad; lingüística aplicada.

\section{Abstract}

We aim in this essay to discuss the ethical and methodological challenges in research works in the domain of literacy studies, within the field of applied linguistics. To do this, we will rely upon research design carried out in the group Letramento do Professor (Teachers' literacy). Focused in the ethical approach of research work, the field of Literacy studies has been oriented for over two decades towards understanding and acting in settings in which writing (re) establish the strains and conflicts that have, for a long time, historically marginalized large segments of Latin American populations. In the discussion on ethical aspects of research on literacy and teacher training, we highlight the importance of drawing attention to power relations in unequal settings in order to foster confidence among minority or subalternized social groups, such as preservice teachers, thus rethinking the role of researcher as he or she chooses to study such groups.

Keywords: research ethics; methodology; literacy; applied linguistics. 


\section{Introdução}

No campo dos Estudos de Letramento, o enfoque das pesquisas se dá nos usos da escrita, nos valores e nos conhecimentos mobilizados nas práticas sociais em que a escrita tem papel central, sejam estas práticas menos ou mais prestigiadas socialmente. Além disso, as pesquisas buscam compreender e atuar em cenários nos quais a escrita (re)instaura tensões e conflitos que historicamente marginalizaram um grande contingente das populações latino-americanas, mostrando como as relações de poder atuam para definir o que conta como letramento em diferentes contextos.

O objetivo de mostrar o que os sujeitos fazem com a escrita e os valores atribuídos por eles aos eventos de letramento de que participam, de modo a entender a agência social desses sujeitos, traz como decorrência um compromisso ético com os grupos participantes da pesquisa. Trazer suas vozes para o contexto da discussão acadêmica e procurar compreender tais vozes na relação com outros grupos que se cruzam nesses eventos de letramento é uma maneira de visibilizá-los para a pesquisa científica e, com isso, contribuir para a legitimação de suas práticas de letramento.

Com a adoção desses pressupostos, nas últimas décadas, as pesquisas que se desenvolveram na abordagem sociocultural dos Estudos de Letramento permitiram o reconhecimento de uma realidade social em que coexistem múltiplos letramentos, não uma única habilidade neutra e técnica - mas múltiplas e heterogêneas formas de utilizar a escrita (Street, 1984, 1993; Kleiman, 1995; Barton e Hamilton, 2000). Tal percepção é possibilitada por pesquisas etnográficas ou de cunho etnográfico, em que os pesquisadores se inserem nos contextos pesquisados a fim de investigar as práticas de letramento de maneira situada e em sua relação com o contexto social mais amplo, evitando, assim, análises de eventos isolados.

Diante disso, neste ensaio, buscamos discutir os desafios éticos e metodológicos que se colocaram para as pesquisas realizadas na área dos Estudos de Letramento, no campo da Linguística Aplicada, pelas autoras, inseridas no Grupo de pesquisa Letramento do Professor ${ }^{1}$.

Para isso, este texto se organiza da seguinte maneira: na próxima seção, discutimos as contribuições do caráter transdisciplinar e indisciplinar da Linguística Aplicada para as pesquisas no campo dos Estudos de Letramento no Brasil. Em seguida, tratamos de alguns desafios que se colocaram para as autoras em trabalhos realizados, todos desenvolvidos tendo em vista o letramento situado do professor, em uma perspectiva etnográfica de pesquisa. Por fim, tecemos algumas considerações.

\section{Linguística Aplicada, Estudos de Letramento e as vozes do sul}

A Linguística Aplicada (doravante, LA) é caracterizada como campo transdisciplinar por se voltar para problemas sociais em que os usos da linguagem têm papel central (Moita-Lopes, 2006), visando a objetivos transformadores e intervencionistas por meio da escolha de temas que tenham impactos no mundo social (Fabrício, 2006). As pesquisas em LA que seguem uma postura crítica perante a linguagem adotam uma orientação explícita para o desenvolvimento de uma agenda política, transformadora/intervencionista e ética, por isso também chamada indisciplinar, "decorrente da ideia de que nossas práticas discursivas envolvem escolhas que têm impactos diferenciados no mundo social e nele interferem de formas variadas" (Fabricio, 2006, p. 49).

1 O grupo Letramento do Professor constituiu-se em 1991, no Departamento de Linguística Aplicada da Unicamp, em resposta a uma solicitação de uma secretaria municipal para assessoria na área de formação de alfabetizadores de adultos. O grupo reúne diversos pesquisadores de diferentes instituições que investigam as práticas sociais de uso da escrita de agentes de letramento escolar e não escolar, levando em conta seus contextos de atuação e a formação de uma identidade profissional. 
A postura crítica não influencia somente os objetivos de pesquisa, mas também a escolha dos objetos de pesquisa. Primeiramente, por sua complexidade, esses objetos requerem o recurso a várias áreas de conhecimento, o que justifica o enfoque transdisciplinar, que empresta conceitos e teorizações de outras áreas, combinados, revisitados e revisados tendo em vista os contextos de pesquisa do linguista aplicado, evitando o risco de ecletismo de áreas muito amplas e gerando possibilidades de teorizações próprias da LA (Kleiman; De Grande, 2015). Além disso, a escolha do objeto se estabelece por meio de compromissos sociais com realidades que envolvem demandas de grupos periféricos em relação aos valores sociais canônicos, que sofrem diferentes tipos de desigualdades e de privações (Kleiman, 1992; Celani, 1992; Moita-Lopes, 2006; Kleiman, 2013; Rojo, 2013).

As questões de pesquisa escolhidas por um linguista aplicado ganham ainda outro desenho quando consideramos a realidade brasileira e também latino-americana. De acordo com Kleiman (2013), um linguista aplicado brasileiro não pode esquecer o lugar em que são produzidos conhecimentos, identidades e relações em jogo na pesquisa: "desde um espaço-tempo que sofreu séculos de colonização, um lócus que marca os nossos corpos, as nossas palavras" (p. 43) e, como defende a autora, deveria marcar nossas epistemes. A proletarização do professor, a exclusão e o ensino na escola pública, conflitos e interculturalidade na formação docente são alguns dos temas indicados por Kleiman (2013) como interessantes para o linguista aplicado que quer investigar "com olhos do sul, para o sul, de uma posição de vantagem porque é fronteiriça e ao mesmo tempo exterior, ocupando, assim, uma terceira, diferente e privilegiada posição" (Kleiman, 2013, pp. 50-51).

Como pesquisadoras do grupo Letramento do Professor, nossos objetos de pesquisa são contextos em que o professor e outros agentes de letramento atuam. Os professores, na conjuntura atual, formam um grupo cujos saberes não são legitimados por aqueles que têm vozes poderosas socialmente, como a academia, a grande imprensa e o Estado. Muitas vezes, a avaliação do que faz o professor da escola básica se baseia em parâmetros acadêmicos ou mesmo literários, principalmente os relacionados à escrita. Esta, como mostram pesquisas do grupo Letramento do Professor, pode se tornar um poderoso mecanismo de constituição da subalternidade dos docentes, mas também pode ser usada para subverter essa subalternidade (Kleiman, 2006, 2013; Vóvio, 2007; Valsechi et al., 2014; Kleiman, Vianna, De Grande, 2013).

Tendo em vista o poder social da escrita em nossa sociedade grafocêntrica, para desafiar e combater visões estereotipadas do professor e de sua relação com a escrita, a postura indisciplinar da LA se articula aos Estudos de Letramento, que contribuem para nossas pesquisas, pois entendem as práticas de letramento como práticas sociais situadas, que variam segundo as instituições, os participantes e as relações de poder que as sustentam e, portanto, não são universais. Em outras palavras, entendemos o letramento como sempre relacionado à situação de comunicação em que a escrita desempenha um papel na interação, dependente dos elementos que constituem essa interação e do contexto sócio-histórico em que ocorre. Diferentemente da grande maioria dos estudos sobre a língua escrita até meados da década de 1980, os Estudos de Letramento não pressupõem a existência de uma correlação entre a aquisição e posse da escrita — principalmente aquela legitimada por instituições como a escola, a academia, a crítica literária, a grande imprensa - e algum efeito social (como ascensão social) ou cognitivo (como inteligência superior).

A concepção de escrita como prática social se desenvolveu, no Brasil, com o trabalho de pesquisadores da LA, que, desde o início, estiveram voltados para problemas sociais relativos aos usos da língua oral ou escrita. Como destacam Kleiman e De Grande (2015), o novo campo de pesquisa trouxe uma mudança na perspectiva dos estudos 
sobre os usos da escrita, até então nas mãos de linguistas que analisavam o texto, ou o discurso, mas não os eventos concretos que tomam por base diferentes práticas sociais de uso da escrita.

Assim, desenvolvemos nossa pesquisa na articulação entre o campo da LA e os Estudos de Letramento, com o objetivo de compreender contextos sociais em que a escrita desempenha papel importante nas negociações entre os participantes, podendo ser instrumento de subalternização ou de subversão das relações de poder estabelecidas provisoriamente. Com isso, buscamos desenvolver e divulgar pesquisas em LA alinhadas a uma postura ética em relação aos grupos de periferia:

uma Linguística Aplicada crítica com uma agenda que, em consonância com sua vocação metodológica interventiva, rompe o monopólio do saber das universidades e outras instituições que reúnem grupos de pesquisadores e intelectuais e toma como um de seus objetivos a elaboração de currículos que favoreçam, por um lado, a apropriação desses saberes por grupos na periferia dos centros hegemônicos e, por outro, a legitimação dos saberes produzidos por esses grupos. (Kleiman, 2013, p. 41)

Para romper com o monopólio do saber de instituições poderosas e legitimar saberes produzidos por grupos periféricos, nossas pesquisas foram desenvolvidas junto a grupos de professores em contextos variados: estágio supervisionado na formação inicial, formação continuada na escola e formação continuada em contexto editorial. Em todas elas, nosso objetivo de ouvir as vozes sociais no discurso dos participantes de pesquisa é não só uma exigência ética e política, advinda da LA, como também um desafio que se coloca para pesquisadores interessados em ouvir as "vozes do Sul” (Moita Lopes, 2006; Kleiman, 2013). Isso porque, dentro da tradição da LA em que nos situamos, não procuramos somente descrever e explicar, pois entendemos que é inevitável, ao escrevermos, também nos posicionarmos em relação ao fato examinado e, se possível, propor soluções para os problemas estudados (Kleiman, 2002), que sejam coerentes com os resultados de pesquisa e com os interesses do grupo participante da pesquisa. Isso se torna um desafio, pois precisamos também cuidar para que nossos resultados de pesquisa não possam ser utilizados para contribuir com a desvalorização desses grupos. (Kleiman, 2002).

Os professores da escola básica podem ser considerados um grupo periférico na medida em que historicamente constituem uma classe à margem da produção do conhecimento socialmente mais valorizado, tendo sido há muitas décadas tratados de fato como "objeto" de comentários, de pesquisas e de tomadas de decisão de outros grupos que atuam na esfera da educação: acadêmicos, editores, burocratas, ou os denominados "especialistas" com espaço na mídia, como alguns economistas, psicólogos e jornalistas que, mesmo sem formação específica na área, se prestam a julgar temas da Educação. Segundo Tardif (2003), apesar de sua posição estratégica na sociedade, os professores são socialmente desvalorizados entre os diferentes grupos que atuam no campo dos saberes. Essa subalternidade muitas vezes se reflete nas pesquisas e em como os pesquisadores tratam a escola e os professores. Conforme Paiva (2005):

[...] entre nós, é cada vez mais recorrente a coleta de dados em instituições de ensino público. Parece haver um consenso tácito de que quem não "paga” pelos seus estudos teria mais obrigação de aceitar a presença de um pesquisador em sua escola. Há, também, um preconceito generalizado contra as escolas públicas e um desejo de expor suas deficiências, sem, contudo, lhes dar o devido retorno, ou ainda, sem fazer uma análise dos riscos que os resultados de uma pesquisa podem representar para a imagem da instituição. Como nos lembra Morin (2003, p. 35), ao discorrer sobre ética, as atividades científicas necessitam de um reforço moral. Segundo o autor, a "moral tem dois tipos de alinhamento: o sentimento de responsabilidade e o sentimento de solidariedade". Nesse sentido, entendo que apontar as falhas no ensino público sem trazer nenhum retorno para os pesquisados apenas contribui para desestabilizar o que já está fragilizado, o que é, no mínimo, irresponsável e não solidário”. (Paiva, 2005, p. 46)

É justamente essa postura decorrente da academia em relação ao professor da escola básica e essa 
representação negativa desses profissionais que são questionadas nas pesquisas do Grupo Letramento do Professor. Tais trabalhos partem do pressuposto de que, ao analisar qualquer prática profissional do professor, o processo de investigação deve considerar o letramento situado, isto é, o letramento no e para o local do trabalho, ou seja, as práticas sociais de uso da escrita realmente necessárias ao professor para exercer sua profissão.

Para compreender e visibilizar o letramento situado do professor, a opção metodológica privilegiada nas pesquisas por nós desenvolvidas é a etnográfica. Consideramos que a formação do professor é um processo identitário construído em situações concretas de uso da linguagem — os eventos de letramento - e que o letramento do professor não é um "mero instrumento para realização do trabalho", e sim um aspecto constituinte de sua atuação profissional (Kleiman, 2009, p. 21). Por isso, a voz e a agência do professor se tornam mais relevantes, e só podem ser compreendidas em seu contexto se nele observadas, acompanhadas, construídas, ou seja, por meio da etnografia.

$\mathrm{Na}$ formulação de problemas de pesquisa no campo dos Estudos de Letramento, considera-se o que ocorre em eventos de letramento e adota-se um olhar etnográfico, direcionado para as particularidades de uso da escrita nas interações entre os participantes do evento, em vez de julgar o que os sujeitos não fazem a partir de uma suposta norma pré-estabelecida, obedecida ou não em um determinado texto. $\mathrm{O}$ campo nasce em pesquisas etnográficas e antropológicas de Heath (1982) e Street (1984) que, ao acompanharem diferentes comunidades e observarem seus usos e funções da escrita, questionaram a visão predominante de que a escrita seria uma tecnologia neutra, superior à oralidade, a qual, uma vez aprendida, traria efeitos positivos universais para quem a domina.

Garcez e Schulz (2015) discutem a contribuição da etnografia para a investigação em contextos educacionais no campo da LA e como esse aporte metodológico contribui para as bases epistemológicas da área. Para os autores, o olhar circunstanciado no trabalho de campo em uma escola foi indispensável para o entendimento do que acontecia em momentos específicos de observação e geração de dados para suas pesquisas. Esse olhar, como destacam os autores, foi tão aproximado à perspectiva dos participantes quanto possível. A partir disso, Garcez e Schulz (2015) defendem que é a possibilidade desse olhar circunstanciado, próximo e bem informado do trabalho de campo guiado por questões específicas de pesquisa sobre o uso da linguagem que tem tornado a etnografia uma escolha metodológica frequente nas pesquisas em Linguística Aplicada.

A etnografia é fundamental para o entendimento de cenários complexos que nos propomos a investigar e compreender em nossas pesquisas. Conforme Garcez e Schultz (2015) salientam, o registro sistemático e minucioso da vida realmente acontecendo nesses contextos - no caso deles, em uma escola da periferia de Porto Alegre - possibilita não apenas realizar trabalhos acadêmicos, mas também fazer parte "do chão da sala de aula vivida, do chão das palavras que construíram a concretude das ações ali realizadas" (Garcez e Schulz, 2015, p. 26), participação esta que faz com que análises de eventos únicos sejam compreendidos em sua inter-relação com outros eventos e com a história dos participantes do contexto. Nas palavras dos autores, a etnografia ${ }^{2}$ possibilita "ver e contar histórias mais completas sobre o que entendemos estar ocorrendo em cenários que queremos conhecer", o que produz conhecimento relevante (Garcez e Schulz, 2015, p. 26).

Como concebemos a LA em sua vocação crítica e interventiva, a etnografia se torna mais interessante, pois a pesquisa assim concebida demanda

2 Os autores partem da definição de Erickson (1990) para trabalho de campo com orientação etnográfica como um método que envolve a participação intensiva e duradoura do pesquisador no cenário escolhido, o registro detalhado do que é observado em termos de notas de campo e coleção de diferentes materiais e documentos, e a subsequente sistematização dos dados. 
olhares circunstanciados (Garcez e Schulz, 2015) para ocorrências reais e únicas, mediadas por práticas de linguagem. A etnografia permite se aproximar do que é percebido pelos reais participantes do contexto de pesquisa e do que é visto como relevante por eles na realidade em que vivem.

Entendemos que nossas pesquisas, inseridas na LA e realizadas sob uma perspectiva etnográfica, renarram e redescrevem a vida social, a fim de suprir uma necessidade de compreendê-la, tal como afirma Moita Lopes (2006). Segundo o autor, esse exercício de renarrar e redescrever a vida social é essencial para que o linguista aplicado possa situar seu trabalho no mundo, em vez de ser tragado por ele ao produzir conhecimento que não responda às questões contemporâneas em um mundo que não entende ou que vê como separado de si como pesquisador. (Moita Lopes, 2006, p. 90).

Assim, compreendemos que nossas análises não revelam uma realidade única e pré-existente; pelo contrário, elas refletem e refratam a realidade de que fazem parte, apreendida dos nossos pontos de vista específicos (Voloshinov, [1929]2002). Da mesma forma, acreditamos que nossos regis$\operatorname{tros}^{3}$ não são coletados imparcial e objetivamente em um contexto pré-existente, do qual não fazemos parte, mas que tais registros são gerados no contexto da pesquisa, de forma que todas essas circunstâncias precisam ser consideradas quando se pretende transformar tais registros em dados de pesquisa. E é por isso que, ao discutirmos a ética em nossos trabalhos, temos de levar em conta toda essa forma de fazer ciência, muito específica de um campo de investigação das Ciências Humanas extremamente aplicado às questões contemporâneas da vida social.

3 Ao discutir possibilidades de metodologias de pesquisas aplicadas em contextos de ensino, Bazarim (2008) diferencia "registro" e "dado", considerando registro todo material que o pesquisador gera ou coleta em seu contexto de pesquisa, ao passo que o dado já diz respeito ao registro que passou por uma seleção inicial do pesquisador, tornando-se alvo de análise.

\section{Por uma ética construída na e para as Ciências Humanas e Sociais}

Vóvio e Souza (2005) reportam os desafios da pesquisa sobre letramento à estratégia de geração de dados que consiga contemplar realidades complexas e multifacetadas e à quantidade e amplitude de registros gerados, dentre outros. Articulamos a estes desafios a questão do atendimento à regulamentação da ética em pesquisas envolvendo humanos, a desistência de participantes da pesquisa, a viabilização de retorno da pesquisa aos participantes e a relação entre visão crítica e não desvalorização do grupo.

É sabido que toda pesquisa envolvendo seres humanos precisa passar por um Comitê de Ética e que somente podem ser iniciadas após sua aprovação. Faz parte das exigências deste Comitê a elaboração de um Termo de Consentimento Livre e Esclarecido (TCLE) a ser assinado pelos participantes que precisa apresentar a proposta da pesquisa, bem como a forma de contribuição do participante, os riscos e benefícios de sua participação e a possibilidade de desistência a qualquer momento.

Um dos pesquisadores da área da linguagem mais envolvidos com a discussão sobre a regulamentação de ética em pesquisa com seres humanos nas Ciências Humanas e Sociais, Pedro Garcez, em texto apresentado aos pesquisadores da ANPOLL ${ }^{5}$, endossa a necessidade de participação mais expressiva de pesquisadores da área da linguagem na construção de uma reflexão sistemática sobre o tema da ética em pesquisa, que transcende as exigências protocolares. Segundo Garcez (2015), a regulamentação de ética em pesquisa envolvendo humanos é de caráter biomédico e bioético, próprio da área da saúde. Não obstante o reconhecimento do status de conquista histórica para a sociedade dessa

4 Segundo Garcez (2015), os primeiros Comitês de Ética em Pesquisa (CEPS) foram criados em 1996, em hospitais universitários.

5 Associação Nacional de Pós-Graduação e Pesquisa em Letras e Linguística. 
regulamentação da pesquisa biomédica, Garcez (2015) critica o caráter estritamente bioético da regulamentação vigente e sua concepção universal de modelo de pesquisa e insiste na inclusão das especificidades éticas de pesquisas que não seguem o padrão experimental, como as etnografias.

Endossando esse debate, posicionamo-nos a favor de Garcez sobre a importância de se incluir outro ethos para a pesquisa no Brasil, que considere as especificidades das Ciências Humanas e Sociais. Especialmente na pesquisa com professores da escola básica, ressaltamos o histórico de desvalorização deste profissional pela própria universidade e por outras esferas socialmente detentoras de poder, tal como discutimos na seção anterior deste texto. Tendo isso em vista, é natural que os professores participantes de pesquisa se sintam temerosos com as construções depreciativas que algumas pesquisas acadêmicas já produziram em relação a suas práticas e seus saberes. Por esse motivo, acreditamos que seja urgente e necessário um esforço, por parte de pesquisas atuais, na tentativa de reparar essa imagem deturpada e fruto de um olhar proveniente do letramento autônomo, isto é, que analisa as práticas de leitura e escrita dissociadas dos eventos nos quais ocorrem e de suas especificidades (cf. Street, 1984).

É nesse contexto que nasce nossa pesquisa, com objetivo de legitimar essas vozes do sul há muito desprestigiadas no cenário acadêmico. Reconhecemos, entretanto, a dificuldade de inserir nossos trabalhos no padrão da regulamentação ética vigente, uma vez que, tendo em vista toda a situação descrita na qual se desenvolvem nossas pesquisas, perguntamo-nos até que ponto seria possível afirmar que os indivíduos que delas participam estariam totalmente esclarecidos a respeito do consentimento anuído - e uma única vez, por meio de assinatura? Retomando as palavras de Fonseca sobre o trabalho investigativo do antropólogo, se o objetivo do pesquisador é justamente chegar na lógica implícita dos fatos, falar dos 'não ditos' do local, adentrar de certa forma no 'inconsciente' das práticas culturais, como podemos imaginar que os informantes preveem todas as consequências de seu consentimento informado? (Fonseca, 2010, p. 214, apud Sarti e Duarte, 2013, p. 22).

Os desdobramentos dessa reflexão nos levam à outra interrogação: como um sujeito que talvez desconheça o universo acadêmico e seus letramentos vai assentir seu consentimento por escrito se os pressupostos dessa prática letrada não são a ele familiares? Ou ainda: como um sujeito que não legitima a figura do pesquisador ${ }^{6}$ vai consentir sua entrada no campo e participação em seus eventos de letramento previamente a um necessário processo de negociação?

A própria noção de "consentimento" de pesquisas etnográficas, ou de cunho etnográfico - como aquelas que focalizam o letramento do professor-, é contraditória ao que propõe a regulamentação atual, pois não se restringe a um documento formal, assinado e acordado previamente à pesquisa empírica, mas é resultante de um trabalho de negociação com os participantes, é

\section{produto das relações que se estabelecem no campo (eventualmente, para além dele), e de acordo com uma lógica relacional e propriamente 'ética', mas que é aquela da comunidade em que nos inserimos, e que determina também que material coletamos e sob quais condições. Exercício básico de qualquer etno- grafia para ser reconhecida como tal. (Cardoso, 2013, pp. 159-160).}

A desconsideração dessas especificidades da pesquisa etnográfica, como a gradual entrada a campo, o processo de negociação entre os sujeitos, somada à impossibilidade de alcance imediato do que a anuência do consentimento implica, dada a imposição de assinatura prévia do TCLE, pode resultar na desistência de participantes da pesquisa, principalmente daqueles que já são conhecedores das relações de poder existentes na comunidade em foco.

6 Para maior discussão a respeito dos conflitos entre pesquisador e sujeito pesquisado em pesquisa sobre letramento, bem como do processo de negociação entre ambos, verificar Souza (2010). 
Durante o desenvolvimento de sua pesquisa de doutorado sobre letramento na formação inicial docente, Valsechi (2016) lidou com o desafio da saída de um de seus participantes da pesquisa, um professor universitário, possibilidade prevista no TCLE, conforme mencionado no início desta seção. O resultado dessa desistência foi a inutilização dos dados gerados, com a autorização de todos os participantes, em um tipo de evento de letramento de que a pesquisadora havia participado: reuniões de corpo docente das disciplinas de estágio supervisionado da instituição. Em decorrência disso, a pesquisa deixou de ter como sujeitos participantes todos professores universitários de estágio da instituição. Neste caso, a desistência do participante não inviabilizou a pesquisa, nem a impactou fortemente, visto não se tratar de sujeitos-chave para os propósitos do estudo e a pesquisadora também contava com uma gama variada de fontes de registros para investigação do seu objeto, o estágio supervisionado, como aulas áudio-gravadas, diários de campo, relatórios de estágio, entrevistas, documentos da universidade.

Com base nesse exemplo facilmente podemos conjeturar outras situações em que a desistência de um participante pode ser prejudicial para a continuidade do trabalho. Se o professor de uma única sala de aula sob investigação, em um estudo de caso, num rompante desiste de participar da pesquisa em andamento, o pesquisador volta para casa sem ter sequer um único registro para dar sequência a seu trabalho? Como lidar, em situações como esta, com os prazos cada vez menores e as exigências de produção científica das instituições acadêmicas? Toda a pesquisa realizada até aquele momento, e o tempo e recursos investidos para essa realização, deveriam ser descartados? A resolução tal como posta atualmente indica que, se a pesquisa ainda está em vigor e o participante decide sair, o pesquisador deve inutilizar os registros até então gerados. E, tendo em vista o exposto, uma situação como essa pode ser extremamente complicada no contexto de nossas pesquisas, especialmente nos casos em que todo o projeto já se delineou tendo em vista o campo e os sujeitos pesquisados, o que é muito comum nos trabalhos que temos realizado. É importante que fique claro que obviamente não estamos com isso defendendo o poder inabalável do pesquisador sobre o pesquisado, de forma a manter uma relação assimétrica entre ambos com a fragilidade sobre este último. Pelo contrário, entendemos que a possibilidade de retirada do estudo é um direito dos sujeitos que deve ser preservado.

É por isso que acreditamos que o ponto fulcral seja justamente o estabelecimento de uma regulamentação específica para atender as necessidades das pesquisas em Ciências Humanas e Sociais envolvendo humanos. Isso porque a retirada dos participantes a qualquer momento do estudo está diretamente ligada ao histórico e ao arcabouço das pesquisas biomédicas, que interferem diretamente na saúde do indivíduo, o qual pode querer parar de fazer testes ou tomar medicações etc. Como as pesquisas em Ciências Humanas ou Sociais se desenvolve em um processo bastante diverso, com seus procedimentos próprios, acreditamos que o consentimento poderia ser construído paulatinamente junto aos participantes, de modo que estes possam compreender bem os propósitos da pesquisa para enfim aceitar participar ou não. Além disso, uma vez tendo aceitado participar, os registros gerados com o consentimento do participante até o momento de sua desistência poderiam ser utilizados nos estudos.

Isso desde que, tal como entendemos a pesquisa em Ciências Humanas, haja por parte dos pesquisadores o comprometimento de que seu trabalho tenha por objetivo fortalecer os grupos pesquisados e contribuir para sua legitimação na sociedade, e não torná-los alvo de ultraje ou difamação, especialmente quando se trata de classes historicamente subalternizadas. Para tanto, é essencial o investimento não apenas na compreensão, por parte dos participantes, dos objetivos e das possibilidades da pesquisa, mas também a garantia do retorno da pesquisa a esses participantes, numa relação mútua de respeito, em que ambas as partes se percebam engajadas em busca de seus propósitos, sejam eles 
para fins acadêmicos ou para o estabelecimento de ações práticas.

Nesse contexto, a visão crítica do pesquisador não implica a desvalorização do grupo participante da pesquisa, mas sim uma busca pela compreensão aprofundada da complexidade dos fenômenos sociais estudados. E os grupos participantes, quando têm oportunidade de conhecer essa possibilidade, podem passar a ver na pesquisa também uma alternativa de busca de soluções e encaminhamentos para questões que fazem parte de suas vidas e seu cotidiano, e com isso certamente terão mais elementos para querer trabalhar em conjunto com os pesquisadores. Mas todo esse processo de reconhecimento e legitimação mútuo (isto é, tanto da pesquisa para o grupo pesquisado, quanto do grupo pesquisado para o pesquisador) demanda tempo e trabalho conjunto, impossível de ser realizado exclusivamente pela assinatura de um documento formal, anterior ao contato mais aprofundado entre as partes.

Uma das maneiras para transformar relações muitas vezes conflituosas entre pesquisador e participantes de pesquisaé o retorno a ser dado sobre os resultados da pesquisa, o que não implica, necessariamente, o envio de uma dissertação de mestrado ou tese de doutorado, que pode ser considerado como um retorno insatisfatório, principalmente a grupos que não estão familiarizados com práticas de letramento acadêmico. A cada pesquisa, a depender do grupo participante, as formas de dar esse retorno e de incluir os participantes no debate sobre a pesquisa realizada podem ser, caso a caso, pensadas e planejadas.

Também acreditamos que o fortalecimento dos grupos estudados por meio de nosso compromisso ético dentro da comunidade acadêmica é uma das maneiras de fazer ouvir suas vozes em meios nos quais elas historicamente não têm prestígio e fazer com que a pesquisa ofereça algum retorno a eles. Em nosso caso, na LA, são estudados especificamente os eventos nos quais o texto escrito tem função privilegiada, cuja análise cuidadosa, acreditamos, pode trazer contribuições tanto para a construção do conhecimento científico, quanto para o aprimoramento das realidades nas quais se desenvolvem nossas pesquisas, entre elas as variadas ações de formação continuada de professores oferecidas por instituições diversas (universidades públicas ou privadas, órgãos governamentais, empresas privadas) ou, ainda, desenvolvidas pela mobilização dos próprios profissionais docentes em suas atribuições na escola básica.

As análises das pesquisas, sob essa perspectiva, vão além da simples crítica a um ou outro grupo social, pois têm em si realmente a função salientada por Moita Lopes (1994) de interferir no mundo, compreendê-lo melhor para, quem sabe, contribuir de fato para melhorá-lo.

\section{Considerações finais: possibilidades para enfrentar os desafios}

Como pesquisadoras inseridas em uma vertente da Linguística Aplicada que se autodenomina indisciplinar e que verdadeiramente preza pela dignidade dos sujeitos que participam de seus estudos, consideramo-nos defensoras ativas da busca por uma postura ética na pesquisa acadêmica. Entretanto, conforme expusemos no presente texto, reconhecemos a urgência de uma adequação dos parâmetros e exigências dos Comitês de Ética em Pesquisa no que diz respeito às Pesquisas em Ciências Sociais e Humanas. Isso, porque os atuais critérios claramente foram estipulados com base em estudos desenvolvidos na área das Ciências Biomédicas, os quais têm natureza completamente diversa das pesquisas sociais da Linguística Aplicada, especificamente no campo da formação docente, ao qual nos filiamos.

Dada a diversidade na maneira de conduzir o trabalho científico, é evidente que os modelos e roteiros das pesquisas biomédicas não podem ser aplicados sem restrições ao contexto das ciências humanas e é por esse motivo que iniciativas como a de Garcez (2015), mencionada em seção anterior, ganham eco em nossas vozes de também pesquisadoras da área de humanas. Um dos elementos que necessitam de 
adequação, ao qual nos detivemos neste ensaio, é o TCLE e todo o processo que envolve a sua assinatura nos moldes como é realizado atualmente.

Para muito além da modificação de um documento com fins burocráticos, entendemos que seja imprescindível o esforço das instituições de pesquisa e de seus respectivos pesquisadores em construir e resgatar, com os indivíduos que venham a participar de pesquisas, a confiança na função social da ciência. Assim como acreditamos, como linguistas aplicadas, que podemos, por meio de nossos trabalhos interferir no mundo, compreendê-lo melhor para, então, modificá-lo e torná-lo mais justo, os possíveis sujeitos de futuras pesquisas também podem passar a acreditar nessa função e nessa possibilidade da pesquisa científica se perceberem que têm também a ganhar com tais trabalhos de pesquisa. É extremamente importante, nesse sentido, que os projetos de pesquisa sejam vistos não apenas como pontos a mais no currículo pessoal do pesquisador, mas como um meio de ação social em busca de uma sociedade mais justa e igualitária.

Em outras palavras, instituir uma agenda de pesquisa que lide com grupos subalternizados, tal como propomos em uma LA desde o sul, para o sul, implica utilizar os resultados da pesquisa para interferir de alguma forma no meio pesquisado, seja ratificando práticas instituídas, seja legitimando práticas libertadoras, seja sugerindo mudanças, seja apontando novos caminhos, entre diversas outras possibilidades de agir no mundo por meio de uma pesquisa socialmente engajada.

\section{Referências}

Barton, D.; Hamilton, M. (2000). Literacy practices. Em D. Barton, M. Hamilton e R. Ivanic, Situated literacies: Reading and writing in context. Lôndres e Nova Iorque: Routledge.

Bazarim, M. (2008). Metodologias de pesquisa aplicadas ao contexto de ensinoaprendizagem de línguas. Congresso Nacional de Lingüistica e Filologia, 12, 93-102, Rio de Janeiro, RJ, Brasil.
Cardoso, M. (2013). Etnografia entre "éticas": ética e pesquisa com populações indígenas. Em C. Sarti, L. F. D. Duarti (Orgs.), Antropologia e ética: desafios para a regulamentação (pp. 131-171). Brasília: ABA.

Celani, M. A. A. (1992). Afinal, o que é Linguística Aplicada? Em M. S. Z. Paschoal, M. A. A. Celani, (Orgs.), Linguistica Aplicada: da aplicação da linguistica à linguistica transdisciplinar (pp. 15-23). São Paulo: EDUC.

Erickson, F. (1990). Qualitative methods. Em L. Linn Robert L. Linn e Frederick Erickson (Orgs.), Qualitative methods (vol. 2). Nova Iorque: Macmillan.

Fabrício, B. F. (2006). Lingüística Aplicada como espaço de desaprendizagem: redescrições em curso. Em L. P. Moita-Lopes, (Org.), Por uma Linguística Aplicada indisciplinar. São Paulo: Parábola Editorial.

Garcez, P.M. (2015). Regulamentação ética em pesquisa com seres humanos específica para as Ciências Humanas e Sociais no âmbito do Ministério da Saúde do Brasil: descaso, desconhecimento, confronto, diálogo e ruptura. Disponível em: <<http:// http://anpoll. org.br/portal/wp-content/uploads/2015/03/ Garcez-p-ANPOLL-\%C3\%A9tica-em-pesquisa-05.03.15.pdf $>>$.

Garcez, P. M. e Schulz, L. (2015). Olhares circunstanciados: etnografia da linguagem e pesquisa em Linguística Aplicada no Brasil. DELTA, 31-especial, 1-34.

Heath, S. B. (1982). What no bedtime story means: narrative skills at home and school. Language and Society, (11), 49-76.

Kleiman, A. (1992). O ensino de línguas no Brasil. Em A. A. Celani e M. Z. Paschoal, (Orgs.), Lingüistica Aplicada: da aplicação da lingüistica à lingüistica transdiciplinar (pp. 25-36). São Paulo, S.P.: Cortez.

Kleiman, A. (1995). Modelos de letramento e as práticas de alfabetização na escola. Em A. Kleiman, Os significados do letramento. Campinas, s.P.: Mercado de Letras.

Kleiman, A. (2002). A interface de questões éticas e metodológicas na pesquisa em Linguística Aplicada. Em D. E. G. Da Silva, e J. A. Vieira, (Orgs.), Análise do discurso: percursos teóricos e metodológicos (pp. 187 202). Brasília: UnB, Plano.

Kleiman, A. (2006). Professores e agentes de letramento: identidade e posicionamento social. Revista Filologia e Linguística Portuguesa, (8), São Paulo.

Kleiman, A. (2009). Projetos dentro de projetos: ensino-aprendizagem da escrita na formação de professores de nível universitário e de outros agentes de letramento. Scripta, 13(24), 17-30. 
Kleiman, A. (2013). Agenda de pesquisa e ação em Linguística Aplicada: problematizações. Em L. P. Moita Lopes, Linguistica Aplicada na modernidade recente: Festschrift para Antonieta Celani. São Paulo: Parábola.

Kleiman, A., Vianna, C., e De Grande, P. B. (2013). "Sem querer ir contra pessoas tão ilustres...”: construção e negociação identitárias do professor entre discursos de (des)legitimação. Scripta, 17(32).

Kleiman, A. e De Grande, P. B. (2015). Interseções entre a linguística aplicada e os estudos de letramento: desenhos transdisciplinares, éticos e críticos de pesquisa. Matraga, 22(36).

Moita Lopes, L. P. (1994). Pesquisa interpretativista em Lingüística Aplicada: a linguagem como condição e solução. Delta, 10(2), 329-338.

Moita Lopes, L. P. (2006). Uma Linguística Aplicada mestiça e ideológica. Interrogando o campo aplicado como linguista aplicado. Em L. P. Moita Lopes (Org.), Por uma Linguistica Aplicada indisciplinar. São Paulo: Parábola.

Paiva, V. L. M. (2005). Reflexões sobre ética e pesquisa. Rev. Brasileira de Linguística Aplicada, 5(1), 45-61.

Rojo, R. (2013). Caminhos para a LA: política linguística, política e globalização. Em C. Nicolaides, K. A. Silva, R. Tilio e C. Hilsdorf, (Orgs.), Politica e politicas linguisticas. Campinas, sp: Pontes.

Sarti, C., Duarti, L. F. D. (Orgs.) (2013). Antropologia e ética: desafios para a regulamentação. Brasília: ABA.

Souza, A. L. S. (2010). Letramentos de reexistência: culturas e identidades no movimento hip-hop. Tese de doutorado, Linguística Aplicada, Instituto de Estudos da Linguagem, Universidade Estadual de Campinas, Campinas.
Street, B. (1984). Literacy in theory and practice. Cambridge: Cambridge University Press.

Street, B. (1993). The new literacy studies. Em B. Street (Org.), Cross-cultural approaches to literacy. Cambridge: Cambridge University Press.

Tardif, M. (2003). Saberes docentes e formação profissional (3. ${ }^{\mathrm{a}}$ ed). Petrópolis, RJ: Vozes.

Valsechi, M. C., Sito, L. S., De Grande, P. B., Pereira, S. L., Vianna, C. S. D. (2014). Legitimação dos participantes e rompimento de assimetrias: contribuições do grupo letramento do professor para o campo dos estudos de letramento. Em Anais do $5^{\circ}$ Colóquio Internacional Letramento e Cultura Escrita. Belo Horizonte, MG.

Valsechi, M. C. (2016). Afinal, o que é o estágio supervisionado? De labirinto a entrelugar: o estágio proposto pela universidade na visão dos estagiários. Tese de doutorado. Linguística Aplicada, Instituto de Estudos da Linguagem. Universidade Estadual de Campinas, Campinas.

Volochinov, V. N. ([1929]2002). Marxismo e filosofia da linguagem. São Paulo: Hucitec.

Vóvio, C. L., e Souza, A. L. S. (2005). Desafios metodológicos em pesquisas sobre letramento. Em A. Kleiman, M. L. Matencio, (Orgs.). Letramento e formação do professor: práticas discursivas, representações e construção do saber (pp. 41-64). Campinas: Mercado de Letras.

Vóvio, C. L. (2007). Entre discursos: sentidos, práticas e identidades leitoras de alfabetizadores de jovens e adultos. Tese de doutorado, Linguística Aplicada. Instituto de Estudos da Linguagem. Universidade Estadual de Campinas, Campinas.

How to reference this article: P. B. De Grande, M. C. Valsechi, e C. A. Dias Vianna (2019). Desafios éticos e metodológicos em pesquisas sobre letramento do professor: provocações em busca de novos caminhos. Íkala, Revista de Lenguaje y Cultura, 24(2), 331-342. Dor: 10.17533/udea.ikala.v24n02a08 